\title{
Associations between obesity (BMI and waist circumference) and socio-demographic factors, physical activity, dietary habits, life events, resilience, mood, perceived stress and hopelessness in healthy older Europeans
}

Barbara Stewart-Knox ${ }^{1 *}$, Maresa E Duffy ${ }^{1}$, Brendan Bunting ${ }^{2}$, Heather Parr ${ }^{1}$, Maria Daniel Vas de Almeida ${ }^{3}$ and Mike Gibney ${ }^{4}$

\begin{abstract}
Background: It is important to understand the psycho-social context of obesity to inform prevention and treatment of obesity at both the individual and public health level.

Methods: Representative samples of middle-aged adults aged $\geq 43$ years were recruited in Great Britain (GB) $(n=1182)$ and Portugal $(n=540)$ and interviewed to explore associations between body mass index (BMI), waist circumference (WC), demographic factors, physical activity, dietary habits (FFQ), life events (LES), Resilience (RS11), Mood (MS), Hopelessness (BDI) and Perceived Stress (PSS4). BMI $\left(\mathrm{kg} / \mathrm{m}^{2}\right)$ and WC $(\mathrm{cm})$ were dependent variables in separate multiple linear regression models for which predictors were entered in 4 blocks: 1 . demographic factors; 2. stressful life events; 3. diet/activity; and, 4. psychological measures.
\end{abstract}

Results: In the GB sample, BMI $\left(\mathrm{kg} / \mathrm{m}^{2}\right)$ was predicted by less education, illness in a close friend or relative, frequent alcohol consumption and sedentary behaviour. Among the Portuguese, higher BMI $\left(\mathrm{kg} / \mathrm{m}^{2}\right)$ was predicted by lower resilience. Being male and less education were independent predictors of having a larger WC $(\mathrm{cm})$ in both countries. Within GB, not working, illness in a close friend or relative, sedentary lifestyle and lower resilience were also independent predictors of a larger WC $(\mathrm{cm})$.

Conclusions: These data suggest that intervention to treat and/or prevent obesity should target males, particularly those who have left education early and seek to promote resilience. In GB, targeting those with high alcohol consumption and encouraging physical activity, particularly among those who have experienced illness in a close friend or relative may also be effective in reducing obesity.

Keywords: Waist circumference, BMI, Obesity, Psychological well-being, Stress, Hopelessness, Resilience, Mood, Lifestyle, Life events, Survey, Lipgene

\footnotetext{
* Correspondence: B.knox@ulster.ac.uk

${ }^{1}$ Northern Ireland Centre for Food \& Health (NICHE) School of Biomedical

Sciences, University of Ulster, Coleraine, Northern Ireland

Full list of author information is available at the end of the article
} 


\section{Background}

Obesity rates and associated co-morbidity are increasing globally [1] and are attributed to detrimental lifestyle practices [2, 3]. Socio-demographic factors appear to interplay with lifestyle to drive obesity. Obesity rates tend to be higher among the socioeconomically deprived [3-5] and the less educated [3, 6-8]. There may be sex differences in how socio-demographic factors interact in obesity [4]. There is also some evidence to suggest that obesity rates are higher among those who have experienced adverse social circumstances [9]. There is growing interest in the psychology of health [10,11], lifestyle [12] and obesity [13]. That obesity is common among those diagnosed with clinical psychosis $[14,15]$ has sparked the notion that obesity may be linked to psychological health and well-being. Previous studies of obesity and psychological well-being among healthy adults have almost exclusively considered depression and to a lesser extent stress. Evidence for an association between BMI $\left(\mathrm{kg} / \mathrm{m}^{2}\right)$ and depression [16-22] and/or stress [23, 24] appears conflicting. Research which has considered waist circumference (WC) and depression and/or stress appears more consistent in that the majority of studies have indicated a link between greater WC $(\mathrm{cm})$ and depression $[17,18,25,26]$. There are a few studies, however, which found no association between $\mathrm{WC}(\mathrm{cm})$ and depression [21-23]. What little research has considered WC $(\mathrm{cm})$ and stress [23] has tended to produce null findings. These disparate findings imply that the relationship between obesity and psychological well-being is complex and worthy of further research.

Cultural differences in associations between well-being and obesity may go some way toward accounting for the conflicting findings reported in the literature. Whilst existing studies have taken place in a range of countries and cultures world-wide, there appears to be a lack of research which has compared more than one culture in the same study. There may also be sex differences in the way that wellbeing, particularly depression, interacts with obesity $[16-18,26]$ and which may also explain the apparent disparity between studies. Previous studies of obesity and well-being have been biased toward the study of negative psychological factors to the neglect of positive traits that may be protective against obesity [11]. Wellbeing can be either eudaimonic, which is associated with one's sense of autonomy, purpose and personal growth or hedonic which reflects life satisfaction $[10,11]$. Resilience, for example, is a positive trait which has been defined as 'a dynamic process wherein individuals display positive adaptation despite experiences of significant adversity or trauma' [27] and can be considered consistent with the eudaimonic model of wellbeing. Mood, on the other hand, can be construed as a central stable (hedonic) trait, which according to Underwood and Froming [28], comprises three dimensions, happiness/valance, strength/intensity and frequency/reactivity, all of which are associated with sociability. Our research, therefore, has considered not only depression and stress, but also resilience and trait mood. Previous research has also neglected to consider experiential factors that may impact upon well-being and obesity. Experience of stressful life events is likely to interact with resilience [29] and mood [28]. The aim of this study has been to determine, in two representative samples of older adults, whether there is a relationship between anthropometric factors (BMI and WC), lifestyle (frequency of food consumption and physical activity), demographic factors (sex and age), life experiences and psychological wellbeing (mood, resilience, stress and hopelessness) concurrently among healthy older people residing in Great-Britain (GB) and Portugal, whilst exploring interactions with sex. Given that previous studies have indicated that psychological factors interact differently with different anthropometric outcomes, separate models have been developed for BMI and WC anthropometric outcomes.

\section{Methods}

The study was of a cross-sectional survey design conducted during autumn 2006.

\section{Sampling}

Sample recruitment and data collection were undertaken by Ipsos Mori (GB), an international market research company. Nationally representative samples of adults over the age of forty-three years $(\mathrm{N}=1722)$ were recruited in Great Britain (GB) $(\mathrm{n}=1182)$ and Portugal $(\mathrm{n}=540)$ (Table 1). Multi-stage stratified cluster sampling was undertaken using quotas in Great Britain (GB) for gender, social class, working status by gender and working status by region and in Portugal for age gender, location and town size. Each country was divided into regions or strata according to population size and density resulting in 210 sampling points in GB and 138 in Portugal. To ensure that the samples from each participating country were as nationally-representative as possible, responses were weighted by demographic factors for each sampling point based on the official statistics.

Table 1 Anthropometric characteristics between sex and country

\begin{tabular}{|c|c|c|c|c|}
\hline & \multicolumn{2}{|c|}{ GB N $=1182$} & \multicolumn{2}{|c|}{ Portugal $\mathrm{N}=\mathbf{5 4 0}$} \\
\hline & Male & Female & Male & Female \\
\hline & $(n=603)$ & $(n=579)$ & $(n=253)$ & $(n=287)$ \\
\hline Height (M) & $1.76(0.07)$ & $1.62(0.07)$ & $1.69(0.07)$ & $1.58(0.06)$ \\
\hline Waist Circum $(\mathrm{cm})$ & $93.6(10.3)$ & $84.3(12.9)$ & $98.85(12.5)$ & $93.6(13.7)$ \\
\hline $\mathrm{BMI}\left(\mathrm{kg} / \mathrm{M}^{2}\right)$ & $26.89(4.39)$ & $27.09(4.79)$ & $27.00(3.61)$ & $29.51(5.12)$ \\
\hline
\end{tabular}


The source for GB was the Office of National Statistics and for Portugal, INE National Institute of Statistics.

\section{The questionnaire}

Review of the literature informed the selection of questionnaire items and scales. Items derived from validated scales were used under licence or with the permission of the authors. The resulting tool enquired as to demographic information; dietary habits; physical/sedentary activity; resilience; mood; hopelessness; perceived stress; and, life events. Given that a number of psychological variables were considered, to keep respondent fatigue at a minimum, validated short versions of scales were selected for inclusion in the questionnaire.

\section{Food frequency questionnaire (FFQ)}

A food frequency questionnaire (FFQ) was derived from that used previously in the Zenith study of healthy ageing [30] and then abridged, piloted and employed as a measure of how often ten different food groups (dairy; meat/poultry; fish/eggs; bread/cereals; confectionary/ bakery; spreads; oils; fruit/vegetables; wine; and, other alcoholic drinks) were consumed. Responses were on a Likert scale ranging between $0-6$ (never $<1$ once per month; $1-3$ per month; 1 per week; $2-6$ per week; $1-3$ times per day, 4 times per day, 5 or more per day). 'Exploratory factor analysis was conducted on the FFQ using Maximum Likelihood Extraction and Promax rotation. Three factors with eigenvalues $>1$, accounting for $47 \%$ of the total variance, indicated three distinct dietary profiles: Factor 1 - 'Alcohol' characterised by frequent alcohol (0.999) and wine (0.305) consumption; Factor 2 'Unhealthy' characterised by frequent consumption fat spreads (0.617), sweets/cakes/chocolate/biscuits (0.465), dairy produce $(0.451)$ and bakery products $(0.422)$; Factor 3 - 'Healthy' characterised by frequent intake of fish/ eggs (0.459), vegetable oil (0.386) and wine (0.355) and infrequent intake of bakery products $(-0.259)$. Based on this result each factor score (high alcohol; healthy; and, unhealthy) was entered into the regression analysis.

\section{Physical activity}

Physical activity and sedentary behaviour were assessed using a scale previously employed in the Zenith study [30]. Higher scores denoted greater sedentary behaviour on 'weekdays' and 'weekends' by indicating one of the following: On a week/weekend day (1) I spend up to 1 hour sitting down; (2) I spend over 1 to up to 4 hours sitting down; (3) I spend over 4 to up to 7 hours sitting down; (4) I spend over 7 to up to 9 hours sitting down; (5) I spend more than 9 hours sitting down; (6) None of these; (7) Don't know/can't remember. Physical activity was indicated in response to 'within the last week I have spent at least 30 minutes on continuous physically activity (for example walking)' (1) once or twice; (2) 3-5 times (3) 6-7 times (4) More than 7 times (5) None of these (6) Don't know/ can't remember. The equally weighted summed scores for weekend and weekday sedentary behaviour were entered into the regression analysis along with physical activity score.

\section{Resilience scale (RS11)}

The validated 11-item version of the 25-item Resilience Scale (RSS) developed by Wagnild and Young (1993) [31] was used to assess resilience. The full version (RSS) and the 11-item short (RS11) have been shown to have good internal consistency of between $\alpha 0.76$ and 0.91 [31] and good concurrent validity [32]. Responses were on a 7-point Likert scale (agree/disagree) or 'don't know'. All 11 items loaded onto a single factor. Factor loadings for the items were as follows: 'When I make plans I follow through with them' (0.635); 'I usually manage one way or another' (0.69); 'Keeping interested in things is important to me' (0.744); 'I am friends with myself' (0.70); 'I feel I can manage many things at a time' (0.699); 'I am determined' (0.713); 'I keep interested in things' (0.755); 'I can usually find something to laugh about' (0.677); 'I can usually look at a situation in a number of ways' (0.697); 'Sometimes I make myself do things whether I want to or not' (0.488); 'I have enough energy to do what I have to do' (0.582). The model was adjusted using correlated errors (items 7 with $3 ; 7$ with 6; 9 with $8 ; 10$ with $4 ; 6$ with 1 , and, 2 with 1 ). The model fit statistics were as follows: $\mathrm{CFI}=0.979$; $\mathrm{TLI}=$ 0.969 ; $\mathrm{RMSEA}=0.043$; and, $\mathrm{SRMR}=0.023$. The reliability of the RS11 for the purpose of this study was $\alpha=.90$. An equally weighted summed index was created from the 11 items and included within the regression analysis.

\section{Mood survey}

The validated 3-item version of the mood survey developed by Underwood and Froming (1980) [28] was employed to assess mood as a stable trait rather than as state. The items were: mood valance 'How happy are you in general?'; mood variability 'How frequently do your moods change?'; and, mood intensity 'How intensely do you react to experiences?'. Responses were on a 9-point Likert scale or 'don't know'. Each item was entered individually into the regression analysis.

\section{Beck hopelessness scale (BHS)}

This 20-item Beck Hopelessness Scale (BHS) was originally developed by Beck and colleagues in 1974 [33] to measure the extent of negative expectations/attitudes relating to the immediate and long-term future. The BHS has been shown to have good internal consistency $(\alpha$ $0.82-0.93)$ and good predictive validity (0.91) [33]. On the basis of factor structure [33], eight items were 
derived from the BHS and included in the model. Responses were dichotomous (agree/disagree) or 'don't know'. A one factor confirmatory model was tested by weighted least squares means and variances (CFI $=0.948$ and $\mathrm{TLI}=0.965$; RMSEA $=0.028$ ): 'I might as well give up because there is nothing I can do about making things better for myself' (0.693); 'When things are going badly, I am helped by knowing that they cannot stay that way forever' (-0.322); 'I just can't get opportunities and there's no reason I will in the future' (0.809); 'All I can see ahead of me is unpleasantness rather than pleasantness' (0.716); 'I don't expect to get what I really want' (0.627); 'I never get what I want so it's foolish to want anything' (0.741); 'It's very unlikely that I will get any real satisfaction in the future' (0.775); 'There's no use in really trying to get anything I want because I probably won't get it' (0.734). Scores from all 8 items were summed into an equally weighted index and included in the regression analysis.

\section{Perceived stress scale (PSS)}

The validated 4-item version [34] of the Perceived Stress Scale PSS scale devised by Cohen and colleagues (1983) [35] has been used for this study. Responses were on a 75-point Likert scale 'never-very often' or 'don't know'. A two factor model was used to describe the data. Two items loaded onto factor 1 'emotional stress': 'In the last month, how often have you felt confident about your ability to handle your personal problems?' (0.870); 'In the last month, how often have you felt that things were going your way?' (0.636). Two items loaded onto factor 2 'stress control': 'In the last month, how often have you felt that you were unable to control the important things in your life?' (0.719); 'In the last month, how often have you felt difficulties were piling up so high that you could not overcome them?' (0.782). The correlation coefficient between the two factors was 0.397 . The overall reliability of the four items was $\alpha=0.71$. An equally weighted summed index of the items, which loaded onto each of the factors, was entered into the linear regression analysis as one variable.

\section{Life events scale (LES)}

The 10-item Life Events Scale (LES) developed by Mooy et al. (2000) [36] was used to record the occurrence (or not) of: (a) serious or long lasting problems with a partner; (b) end of a significant or long-term relationship; (c) serious or long-term financial problems; (d) personal long-term illness or disability; (e) personal long-term illness or disability lasting more than six months; (f) serious or long-term illness or disability of a child; ( $g$ ) serious or long lasting social or behavioural problems with a child; (h) death of someone close to you (child/ partner/sibling/close friend); (i) Forced job change/loss of job/retirement; and, (j) serious or long lasting stress at work. These dichotomous items were collapsed into five variables semantically described as: 'relationship problems' (a and b); 'financial difficulties' (c); 'illnesses' (d, e, $\mathrm{f}$ and g); 'bereavement' (h); and, 'job difficulties' (i and j) which were entered into the multiple regression analysis.

\section{Procedure}

Ethical approval for the survey was granted by the Office of Research Ethics Committee Northern Ireland (ORECNI). Fieldworkers in both countries were trained and in the employment of the market research company (IPSOS Mori). Respondents provided written (informed) consent before taking part. Omnibus survey employing a representative sample recruited in Great Britain and Portugal was undertaken during January 2006. Data were collected in each individual's own home by interview. Cue cards were used to present the response options for each item. Anthropometric measurements were taken following completion of the questionnaire. Waist circumference was measured by means of a tape measure at the level of the umbilicus in males and at the narrowest diameter in females. BMI $\left(\mathrm{kg} / \mathrm{m}^{2}\right)$ was calculated from height measured by stadiometer and body weight by an electronic scale.

\section{Statistical analysis}

Statistical analyses were undertaken using the SPSS (Version 19.0; SPSS UK Ltd, Chertsey, United Kingdom). Two-way MANOVA was employed to look at differences in anthropometric and demographic characteristics, height $(\mathrm{m})$, WC $(\mathrm{cm})$, BMI $\left(\mathrm{kg} / \mathrm{m}^{2}\right)$ and age (years) between country and sex. Associations between the independent variables (Resilience Scale, Mood Survey, Beck Hopelessness Scale and Perceived Stress Scale (emotional stress and stress control scores) and the dependent variables WC $(\mathrm{cm})$ and BMI $\left(\mathrm{kg} / \mathrm{m}^{2}\right)$ were examined by multiple linear regression analysis. The GB and Portugal samples were analysed separately to establish which independent variables were the best predictors of BMI $\left(\mathrm{kg} / \mathrm{m}^{2}\right)$ and WC $(\mathrm{cm})$ within each country. The aim of the analysis was to establish the degree to which the psychological factors explained/contributed to the variance in BMI $\left(\mathrm{kg} / \mathrm{m}^{2}\right)$ and WC. Demographic information (age; sex; education level), life events (LES) and lifestyle factors (Dietary habits (FFQ) and physical activity (PAQ)) thus were entered first into the analysis so that each could be controlled prior to entry of the psychometric data. The predictors were entered simultaneously in 4 blocks (1. demographic factors; 2 . life events; 3 . diet/activity; 4. psychological measures). Continuous measures (age, years of education and psychometric scores) were adjusted to assess if there were any potential interactions with sex. Variables were centred by subtracting the overall means from each individual 
value and then multiplying by sex to establish if there were any interactions with sex. Mahalanobis distance values indicated that there were no multivariate outliers among the independent variables (i.e. no values greater that the chi-squared value of 37.65) [37]. The adjusted $\mathrm{R}^{2}$ values, Beta values and standard error have been presented for each country (i.e. GB and Portugal).

\section{Results}

\section{Sample description}

The sample $(\mathrm{N}=1722)$ comprised in $\mathrm{GB}(\mathrm{n}=1182) 51 \%$ $(\mathrm{n}=603)$ male and $49 \%(\mathrm{n}=579)$ female and in Portugal $(\mathrm{n}=540) 47 \%(\mathrm{n}=253)$ male and 53\% $(\mathrm{n}=287)$ female. The age range for the total sample was 43-93 years (Table 1). Mean years spent in education among the GB males was 10.77 (sd.8.38) and females was 9.05 (sd.8.38). Among the Portuguese males the mean years spent in education was 5.03 (sd.2.08) and for females it was 4.13 (sd.2.51). This relatively limited amount of time spent in education is typical among the older population in Portugal.

GB males had a smaller WC (cm) than Portuguese males $(P=0.0001)$ and $G B$ females had a smaller WC (cm) than Portuguese females $(\mathrm{P}=0.0001)$ $(\mathrm{F}=(3,1704)=105.94, \mathrm{P}=0.0001)$. There were no differences in BMI $\left(\mathrm{kg} / \mathrm{m}^{2}\right)$ between respondents in Portugal and GB. There were no within sex differences in BMI $(\mathrm{F}(3,1713)=1.32, \mathrm{P}=0.26)($ Table 1$)$.

\section{Anthropometric, demographic factors, lifestyle and wellbeing: GB sample BMI $\left(\mathrm{kg} / \mathrm{m}^{2}\right)$}

Fewer years spent in education $(\beta-0.12, \quad \mathrm{P}=0.01)$ accounted for $1 \%$ of the variance in BMI $\left(\mathrm{kg} / \mathrm{m}^{2}\right)$ $(\mathrm{F}(6,926)=2.36, \mathrm{P}=0.03)$. Having reported 'illness-related' life events $(\beta=-0.14$. $\mathrm{P}=0.0001)$ explained an further $2 \%$ (i.e. $3 \%)$ of the variance in BMI $\left(\mathrm{kg} / \mathrm{m}^{2}\right)(\mathrm{F}(11,921)=3.36$, $\mathrm{P}=0.000)$. Having a high alcohol consumption $(\beta=-0.07$, $\mathrm{P}=0.04)$ and sedentary behaviour $(\beta=0.14, \mathrm{P}=0.0001)$ contributed a further $2 \%$ (i.e. $5 \%$ ) of the variance in BMI $\left(\mathrm{kg} / \mathrm{m}^{2}\right)(\mathrm{F}(16,916)=3.91, \mathrm{P}=0.0001)$. The inclusion of the psychological variables within model 4 did not further explain the variance in BMI $\left(\mathrm{kg} / \mathrm{m}^{2}\right)$ but improved the model to $6 \%(\mathrm{~F}(26,906)=3.07, \mathrm{P}=0.0001)$ (Table 2).

\section{$W C(\mathrm{~cm})$}

Demographic factors (model 1) including, sex (being male) $(\beta=0.38, P=0.0001)$, fewer years in education $(\beta=-0.12, \quad \mathrm{P}=0.009)$, age ${ }^{*}$ sex (being older and male) $(\beta=0.11, \quad P=0.02)$ and working status (unemployed) $(\beta=-0.08, P=0.02)$ accounted for $16 \%$ of the variance in WC $(F(6,910)=30.692, P=0.0001)$. When life events (model 2) were added to the model, 'illness-related' events predicted a larger WC $(\mathrm{cm})(\beta=0.15, \mathrm{P}=0.0001)$, which together with demographic factors explained a further $2 \%$ of the variance (i.e. $18 \%)$ in $\mathrm{WC}(\mathrm{cm})(\mathrm{F}(=11$, $905)=19.39, \mathrm{P}=0.0001)$. The incorporation of lifestyle factors (diet/physical activity) (model 3) indicated that greater sedentary behaviour predicted a larger WC $(\beta=0.14, P=0.0001)$, contributing an extra $2 \%$ of the variance (i.e. 20\%) in $\mathrm{WC} \quad(\mathrm{F}=(16,900)=15.17$, $\mathrm{P}=0.0001)$. The addition of psychological measures (model 4) to the regression model, indicated that lower scores on resilience $(B=-0.11, P=0.04)$ predicted a larger WC $(\mathrm{cm})$. Resilience, therefore, was the only significant psychological predictor variable in the final model (four) which explained $20 \%$ of the variance in WC $(\mathrm{cm})$ $(\mathrm{F}(28,916)=9.18, \mathrm{P}=0.0001)$. Sex had no influence upon psychological variables in determining WC $(\mathrm{cm})$ (Table 3).

\section{Anthropometric, Demographic Factors, Lifestyle and Wellbeing: Portuguese Sample BMI $\left(\mathrm{kg} / \mathrm{m}^{2}\right)$}

Higher BMI $\left(\mathrm{kg} / \mathrm{m}^{2}\right)$ was associated with older age $(B=-0.224, \quad P=0.05)$ and lower resilience scores $(\beta=-0.25, P=0.05)$ (model 4 ) accounting for $1 \%$ of the variance in BMI (Table 4). Demographic characteristics, lifestyle factors and life events did not contribute significantly $(P=0.05)$ to the model.

\section{WC $(\mathrm{cm})$}

Multiple regression analysis indicated that demographic factors (model 1) including, sex (being male) $(B=0.21$, $\mathrm{P}=0.001)$ and fewer years of education $(B=-0.19$, $\mathrm{P}=0.03)$ accounted for $7 \%$ of the variance in $\mathrm{WC}(\mathrm{cm})$ $(\mathrm{F}(6,260)=4.405, \quad \mathrm{P}=0.0001)$. The incorporation of stressful life events (model 2) reduced the variance in WC $(\mathrm{cm})$ by $1 \%(6 \%)(F(11,255)=2.54, P=0.005)$. Lifestyle factors (model 3) contributed an extra 1\% (7\%) $(\mathrm{F}(16,257)=3.08, \mathrm{P}=0.005)$, indicating that greater physical activity predicted a smaller $\mathrm{WC}(\Omega=-0.12, \mathrm{P}=0.03)$. Finally, the incorporation of psychological variables (model 4) weakened the model and reduced variance in WC $(\mathrm{cm})$ by $1 \%$ from model $3(6 \%)(F(28,238)=1.63$, $\mathrm{P}=0.03)$ (Table 5).

\section{Discussion}

Our study is unusual in that it has considered two culturally diverse representative samples of middle aged and older Europeans. To allow for the possibility of cultural differences in how demographic factors, lifestyle and psychological well-being interact with obesity, separate models were constructed for Great Britain (GB) and Portugal. The results indicated differences in which factors best explained obesity within the two countries. BMI among the British was explained by having spent less time in education, having reported illness related 
Table 2 Multiple linear regression analysis predicting BMI $\left(\mathrm{kg} / \mathrm{m}^{2}\right)$ from demographic factors, life events, food habits, physical activity and psychological factors in the Great Britain sample $(N=1182)$

\begin{tabular}{|c|c|c|c|c|c|c|c|c|c|c|c|c|}
\hline \multirow[b]{2}{*}{ Demographics } & \multicolumn{3}{|c|}{ Model 1} & \multicolumn{3}{|c|}{ Model 2} & \multicolumn{3}{|c|}{ Model 3} & \multicolumn{3}{|c|}{ Model 4} \\
\hline & B & SE & Beta & B & SE & Beta & B & SE & Beta & B & SE & Beta \\
\hline Sex & -0.28 & 0.31 & -0.03 & -0.38 & 0.32 & -0.04 & -0.24 & 0.33 & -0.03 & -0.36 & 0.33 & -0.38 \\
\hline Working Status & -0.17 & 0.38 & -0.02 & -0.48 & 0.39 & -0.05 & -0.63 & 0.38 & -0.07 & -0.56 & 0.38 & -0.06 \\
\hline Age (years) & -0.00 & 0.02 & -0.00 & 0.00 & 0.02 & 0.001 & -0.01 & 0.03 & -0.02 & -0.01 & 0.02 & -0.02 \\
\hline Ed (yrs) & -0.07 & 0.03 & -0.12 & -0.06 & 0.03 & -0.11 & -0.06 & 0.03 & -0.10 & -0.06 & 0.03 & $-0.10^{*}$ \\
\hline Age by*sex & -0.04 & 0.03 & -0.06 & -0.03 & 0.03 & -0.06 & -0.25 & 0.03 & -0.04 & -0.64 & 0.03 & -0.06 \\
\hline Ed (yrs) by*sex & 0.03 & 0.04 & 0.03 & 0.03 & 0.04 & 0.02 & -0.02 & 0.04 & 0.03 & 0.03 & 0.04 & 0.04 \\
\hline \multicolumn{13}{|l|}{ Life Events } \\
\hline Relationships & & & & 0.72 & 0.72 & -0.04 & -0.65 & 0.72 & -0.04 & -0.43 & 0.72 & -0.03 \\
\hline Financial & & & & 0.93 & 0.93 & -0.03 & -0.78 & 0.93 & -0.04 & -0.87 & 0.93 & -0.05 \\
\hline Illness & & & & 0.36 & 0.36 & 0.14 & 1.19 & 0.36 & 0.11 & 1.37 & 0.36 & $0.13^{* *}$ \\
\hline Bereavement & & & & 0.35 & 0.35 & 0.006 & 0.09 & 0.35 & 0.01 & 0.15 & 0.35 & 0.01 \\
\hline Employment & & & & 0.52 & 0.53 & 0.04 & 0.54 & 0.51 & 0.04 & 0.58 & 0.52 & 0.04 \\
\hline \multicolumn{13}{|l|}{ Lifestyle } \\
\hline SED activity $1^{\mathrm{a}}$ & & & & & & & -0.38 & 0.09 & 0.12 & 0.37 & 0.09 & $0.13^{* *}$ \\
\hline PA activity $2^{b}$ & & & & & & & -0.07 & 0.11 & -0.02 & -0.04 & 0.11 & -0.01 \\
\hline FFQ (alcohol) & & & & & & & -0.33 & 0.16 & -0.07 & -0.34 & 0.16 & $-0.07 \dagger$ \\
\hline FFQ (unhealthy) & & & & & & & 0.11 & 0.19 & 0.02 & 0.08 & 0.19 & 0.02 \\
\hline FFQ (healthy) & & & & & & & -0.24 & 0.16 & -0.05 & -0.27 & 0.16 & $-0.06+$ \\
\hline \multicolumn{13}{|l|}{ Wellbeing } \\
\hline General Mood & & & & & & & & & & 0.24 & 0.16 & 0.08 \\
\hline Intense Mood & & & & & & & & & & 0.12 & 0.11 & 0.05 \\
\hline Variable Mood & & & & & & & & & & -0.02 & 0.12 & -0.01 \\
\hline Hopelessness & & & & & & & & & & 0.05 & 0.32 & -0.05 \\
\hline Resilience & & & & & & & & & & -0.03 & 0.03 & -0.05 \\
\hline Emotional stress & & & & & & & & & & -0.09 & 0.15 & -0.03 \\
\hline Stress control & & & & & & & & & & -0.11 & 0.13 & -0.05 \\
\hline General mood ${ }^{\mathbf{1}}$ & & & & & & & & & & -0.12 & 0.22 & -0.03 \\
\hline Intense Mood ${ }^{\mathbf{1}}$ & & & & & & & & & & 0.17 & 0.96 & 0.07 \\
\hline Variable Mood ${ }^{\mathbf{1}}$ & & & & & & & & & & -0.04 & 0.16 & -0.01 \\
\hline Hopelessness ${ }^{\mathbf{1}}$ & & & & & & & & & & 0.04 & 0.44 & 0.00 \\
\hline Resilience ${ }^{\mathbf{1}}$ & & & & & & & & & & -0.03 & 0.04 & -0.04 \\
\hline Emotional stress ${ }^{\mathbf{1}}$ & & & & & & & & & & -0.26 & 0.21 & -0.06 \\
\hline Stress control ${ }^{\mathbf{1}}$ & & & & & & & & & & -0.09 & 0.19 & -0.02 \\
\hline Adjusted $\mathrm{R}^{2}$ & & 0.01 & & & 0.03 & & & 0.05 & & & 0.06 & \\
\hline
\end{tabular}

${ }^{*} \mathrm{P}<0.05,{ }^{* * P}<0.01,+10 \%$ significant.

Abbreviations: SED Sedentary, PA Physical activity, FFQ Food Frequency Questionnaire.

$\mathbf{1}^{\mathrm{a}}=$ controlled for sex.

a Sedentary behaviour at weekdays \& weekends; ${ }^{\text {b }}$ Physical activity in the previous week.

events, frequent alcohol consumption and lack of physical activity. The finding that BMI in GB was predicted by alcohol consumption and sedentary behaviour is in keeping with accepted science suggesting that obesity is associated with lifestyle $[2,8]$. The finding that BMI was predicted by having a lower educational level among the
GB sample was also as expected and adds to a growing body of evidence suggesting the importance of targeting disadvantaged segments of society in controlling obesity $[3,6-8]$. The model also suggested that in GB BMI was predicted by having experienced illness themselves or in a close friend or family member, a finding which concurs 
Table 3 Multiple linear regression analysis predicting waist circumference (cm) (WC) from demographic factors, life events, food habits, physical activity and psychological factors in the Great Britain sample $(\mathbf{N}=1182)$

\begin{tabular}{|c|c|c|c|c|c|c|c|c|c|c|c|c|}
\hline \multirow[b]{2}{*}{ Demographics } & \multicolumn{3}{|c|}{ Model 1} & \multicolumn{3}{|c|}{ Model 2} & \multicolumn{3}{|c|}{ Model 3} & \multicolumn{3}{|c|}{ Model 4} \\
\hline & b & SE b & B & b & SE b & B & b & SE b & B & b & SE b & B \\
\hline Sex & 9.58 & 0.77 & $0.38 * *$ & 9.40 & 0.77 & $0.37 * *$ & 9.48 & 0.81 & $0.37 * *$ & 9.23 & 0.82 & $0.36 * *$ \\
\hline Working Status & 2.3 & 0.94 & $0.08 * *$ & 1.38 & 0.95 & 0.05 & 1.05 & 0.94 & 0.04 & 1.21 & 0.94 & 0.05 \\
\hline Age (years) & -0.06 & 0.06 & -0.05 & -0.03 & 0.06 & -0.03 & -0.06 & 0.06 & -0.05 & -0.05 & 0.06 & -0.05 \\
\hline Ed (yrs) & -0.19 & 0.07 & $-0.13^{* *}$ & -0.18 & 0.07 & $-0.12 * *$ & -0.16 & 0.07 & $-0.11 *$ & -0.17 & 0.07 & $-0.11 * *$ \\
\hline Age by*sex & 0.19 & 0.07 & $0.12 *$ & 0.20 & 0.07 & $0.12 *$ & 0.22 & 0.07 & $0.14 * *$ & 0.20 & 0.07 & $0.13^{* *}$ \\
\hline Ed (yrs) by*sex & 0.11 & 0.10 & 0.05 & 0.10 & 0.09 & 0.05 & 0.10 & 0.09 & 0.05 & 0.12 & 0.10 & 0.05 \\
\hline \multicolumn{13}{|l|}{ Life Events } \\
\hline Relationships & & & & -1.09 & 1.77 & -0.03 & -1.24 & 1.76 & -0.03 & -0.78 & 1.77 & -0.02 \\
\hline Financial & & & & 1.03 & 2.28 & 0.02 & 0.63 & 2.27 & 0.01 & 0.52 & 2.28 & 0.01 \\
\hline Illness & & & & 4.34 & 0.88 & $0.15^{* *}$ & 3.58 & 0.88 & $0.13 * *$ & 3.95 & 0.90 & $0.14 * *$ \\
\hline Bereavement & & & & 0.05 & 0.87 & 0.00 & 0.09 & 0.86 & 0.00 & 0.30 & 0.87 & 0.01 \\
\hline Employment & & & & 0.86 & 1.27 & 0.02 & 0.80 & 1.25 & 0.02 & 0.88 & 1.28 & 0.02 \\
\hline \multicolumn{13}{|l|}{ Lifestyle } \\
\hline SED activity $1^{\mathrm{a}}$ & & & & & & & 1.02 & 0.23 & $0.14 * *$ & 0.97 & 0.24 & $0.13 * *$ \\
\hline PA activity $2^{b}$ & & & & & & & 0.19 & 0.28 & 0.02 & 0.22 & 0.28 & 0.02 \\
\hline FFQ (alcohol) & & & & & & & -0.35 & 0.40 & -0.03 & -0.38 & 0.40 & -0.03 \\
\hline FFQ (unhealthy) & & & & & & & 0.01 & 0.45 & 0.00 & -0.02 & 0.45 & 0.00 \\
\hline FFQ (healthy) & & & & & & & -0.30 & 0.39 & -0.02 & -0.39 & 0.39 & -0.03 \\
\hline \multicolumn{13}{|l|}{ Wellbeing } \\
\hline Happy Mood & & & & & & & & & & 0.68 & 0.38 & $0.08 t$ \\
\hline Intense Mood & & & & & & & & & & 0.35 & 0.27 & $0.09+$ \\
\hline Variable Mood & & & & & & & & & & -0.02 & 0.28 & -0.00 \\
\hline Hopelessness & & & & & & & & & & -0.06 & 0.78 & 0.00 \\
\hline Resilience & & & & & & & & & & -0.15 & 0.06 & $-0.11^{*}$ \\
\hline Emotional stress & & & & & & & & & & -0.11 & 0.37 & -0.01 \\
\hline Stress control & & & & & & & & & & -0.33 & 0.22 & -0.07 \\
\hline General Mood $^{\mathbf{1}}$ & & & & & & & & & & -0.35 & 0.55 & -0.03 \\
\hline Intense Mood ${ }^{\mathbf{1}}$ & & & & & & & & & & -0.15 & 0.39 & -0.02 \\
\hline Hopelessness ${ }^{1}$ & & & & & & & & & & -0.01 & 1.07 & 0.00 \\
\hline Resilience ${ }^{\mathbf{1}}$ & & & & & & & & & & 0.06 & 0.10 & 0.03 \\
\hline Emotional Stress ${ }^{1}$ & & & & & & & & & & -0.40 & 0.52 & -0.13 \\
\hline Stress control ${ }^{\mathbf{1}}$ & & & & & & & & & & 0.14 & 0.45 & 0.02 \\
\hline Adjusted $\mathbf{R}^{2}$ & & 0.16 & & & 0.18 & & & 0.20 & & & 0.20 & \\
\hline
\end{tabular}

${ }^{*} \mathrm{P}<0.05,{ }^{* *} \mathrm{P}<0.01,+10 \%$ significant.

Abbreviations: SED Sedentary, PA Physical activity, FFQ Food Frequency Questionnaire.

$1=$ controlled for sex.

${ }^{\text {a }}$ Sedentary behaviour at weekdays \& weekends; ${ }^{b}$ Physical activity in the previous week.

with existing research which has suggested that informal caring at home can be associated with obesity [38]. The mechanism through which educational disadvantage and/or illness in someone close leads to obesity requires further investigation. Further research is also required to better understand the dynamics linking alcohol intake and obesity in GB. More surprising, the only predictors of BMI among the Portuguese were increasing age and lower resilience. The explanatory power of the BMI models, however, was limited, explaining a mere $6 \%$ of the variance in BMI among the British and only $1 \%$ among the Portuguese. The weak predictive power for our models of BMI and the disparity between the two countries, as well as with previous studies which have 
Table 4 Multiple linear regression analysis predicting BMI $\left(\mathrm{kg} / \mathrm{m}^{2)}\right.$ from demographic factors, life events, food habits, physical activity and psychological factors in a Portuguese sample $(N=540)$

\begin{tabular}{|c|c|c|c|c|c|c|c|c|c|c|c|c|}
\hline \multirow[b]{2}{*}{ Demographics } & \multicolumn{3}{|c|}{ Model 1} & \multicolumn{3}{|c|}{ Model 2} & \multicolumn{3}{|c|}{ Model 3} & \multicolumn{3}{|c|}{ Model 4} \\
\hline & B & SE & Beta & B & SE & Beta & B & SE & Beta & B & SE & Beta \\
\hline Sex & -0.55 & 0.57 & -0.06 & -0.67 & 0.58 & -0.08 & -0.90 & 0.66 & -0.11 & -0.78 & 0.70 & -0.09 \\
\hline Working Status & 0.01 & 0.63 & 0.00 & -0.17 & 0.64 & -0.02 & -0.16 & 0.64 & -.018 & -0.10 & 0.65 & -0.01 \\
\hline Age (yrs) & -0.05 & 0.04 & -0.14 & -0.06 & 0.04 & -0.15 & -0.07 & 0.04 & $-0.19+$ & -0.08 & 0.04 & $-0.22 *$ \\
\hline Ed (yrs) & -0.12 & 0.17 & -0.07 & -0.10 & 0.17 & -0.05 & -0.12 & 0.17 & -0.06 & -0.16 & 0.18 & -0.08 \\
\hline Age by*sex & 0.06 & 0.05 & 0.12 & 0.06 & 0.05 & 0.12 & 0.07 & 0.05 & 0.14 & 0.09 & 0.05 & 0.17 \\
\hline Ed (yrs) by*sex & 0.24 & 0.25 & 0.08 & 0.25 & 0.26 & 0.09 & 0.29 & 0.26 & 0.10 & 0.29 & 0.28 & 0.10 \\
\hline \multicolumn{13}{|l|}{ Life Events } \\
\hline Relationships & & & & -0.49 & 2.02 & -0.03 & -0.42 & 2.03 & -0.02 & -0.60 & 2.11 & -0.03 \\
\hline Financial & & & & 1.24 & 2.51 & 0.05 & 1.55 & 2.54 & 0.06 & 1.32 & 2.67 & 0.05 \\
\hline Illness & & & & 1.28 & 0.70 & $0.12 \dagger$ & 1.10 & 0.70 & 0.11 & 1.10 & 0.72 & 0.11 \\
\hline Bereavement & & & & -0.65 & 0.76 & -0.05 & -0.56 & 0.76 & -0.05 & -0.62 & 0.80 & -0.05 \\
\hline Employment & & & & -0.98 & 1.23 & -0.05 & -1.05 & 1.23 & -0.06 & -1.01 & 1.27 & -0.05 \\
\hline \multicolumn{13}{|l|}{ Lifestyle } \\
\hline SED activity $1^{a}$ & & & & & & & 0.18 & 0.34 & 0.04 & 0.28 & 0.21 & 0.09 \\
\hline PA activity $2^{\mathrm{b}}$ & & & & & & & -0.07 & 0.32 & $-0.02+$ & -0.52 & 0.30 & $-0.12 \dagger$ \\
\hline FFQ (alcohol) & & & & & & & -0.17 & 0.33 & -0.03 & 0.29 & 0.36 & 0.06 \\
\hline FFQ (unhealthy) & & & & & & & 0.30 & 0.20 & 0.10 & -0.06 & 0.33 & -0.01 \\
\hline FFQ (healthy) & & & & & & & -0.50 & 0.28 & -0.11 & -0.16 & 0.35 & -0.03 \\
\hline \multicolumn{13}{|l|}{ Wellbeing } \\
\hline General Mood & & & & & & & & & & -0.19 & 0.31 & -0.07 \\
\hline Variable Mood & & & & & & & & & & 0.03 & 0.21 & 0.01 \\
\hline Intense Mood & & & & & & & & & & -0.03 & 0.25 & -0.01 \\
\hline Hopelessness & & & & & & & & & & 0.06 & 0.38 & 0.02 \\
\hline Resilience & & & & & & & & & & 0.09 & 0.05 & $0.25 *$ \\
\hline Emotional Stress & & & & & & & & & & 0.36 & 0.19 & $0.24 t$ \\
\hline Stress control & & & & & & & & & & 0.57 & 0.40 & 0.04 \\
\hline General mood ${ }^{\mathbf{1}}$ & & & & & & & & & & 0.21 & 0.44 & 0.05 \\
\hline Variable mood ${ }^{\mathbf{1}}$ & & & & & & & & & & 0.58 & 2.97 & 0.19 \\
\hline Intense mood ${ }^{\mathbf{1}}$ & & & & & & & & & & 0.24 & 0.34 & 0.07 \\
\hline Hopelessness ${ }^{1}$ & & & & & & & & & & -0.81 & 0.61 & -0.12 \\
\hline Resilience ${ }^{1}$ & & & & & & & & & & -0.11 & 0.07 & $-0.22 \dagger$ \\
\hline Emotional stress ${ }^{1}$ & & & & & & & & & & -0.15 & 0.24 & -0.04 \\
\hline Stress control ${ }^{\mathbf{1}}$ & & & & & & & & & & -0.57 & 0.40 & -0.17 \\
\hline Adjusted $\mathbf{R}^{2}$ & & 0.01 & & & 0.01 & & & 0.00 & & & 0.01 & \\
\hline
\end{tabular}

*P $<0.05$, ${ }^{*} \mathrm{P}<0.01,+10 \%$ significant.

Abbreviations: SED Sedentary, PA Physical activity, FFQ Food Frequency Questionnaire.

$1=$ controlled for sex.

${ }^{\text {a }}$ Sedentary behaviour at weekdays \& weekends; ${ }^{\mathrm{b}}$ Physical activity in the previous week.

considered psychological factors and BMI, could reflect limitations of BMI as an indicator of obesity [13], particularly in populations of short stature (Table 1) such as the Portuguese.

Waist circumference, on the other hand, has been shown to be closely correlated with visceral fat and other factors associated with the metabolic syndrome [13]. Being male and having spent less time in education predicted greater WC among those in both countries. This apparent sex difference contrasts with previous studies that have identified links between depression and midsection obesity exclusively in females [16-18, 26]. These 
Table 5 Multiple linear regression analysis predicting waist circumference (cm) (WC) from demographic factors, life events, food habits, physical activity and psychological factors in a Portuguese sample $(\mathrm{N}=540)$

\begin{tabular}{|c|c|c|c|c|c|c|c|c|c|c|c|c|}
\hline \multirow[b]{2}{*}{ Demographics } & \multicolumn{3}{|c|}{ Model 1} & \multicolumn{3}{|c|}{ Model 2} & \multicolumn{3}{|c|}{ Model 3} & \multicolumn{3}{|c|}{ Model 4} \\
\hline & B & SE & Beta & B & SE & Beta & B & SE & Beta & B & SE & Beta \\
\hline Sex & 5.54 & 1.67 & $0.21 * *$ & 5.63 & 1.70 & $0.21 * *$ & 4.49 & 1.93 & $0.17^{*}$ & 4.70 & 1.97 & $0.17^{*}$ \\
\hline Working Status & -0.53 & 1.95 & -0.02 & -0.56 & 1.98 & -0.02 & -0.54 & 1.97 & -0.02 & -0.61 & 1.99 & -0.02 \\
\hline Age (yrs) & 0.39 & 0.11 & 0.03 & 0.02 & 0.11 & 0.01 & -0.03 & 0.12 & -0.03 & -0.04 & 0.12 & -0.04 \\
\hline Ed (yrs) & -1.07 & 0.49 & $-0.19 *$ & -1.04 & 0.50 & $-0.18^{*}$ & -1.02 & 0.50 & $-0.18^{*}$ & -0.83 & 0.52 & -0.14 \\
\hline Age by*sex & 0.26 & 0.15 & $0.16 t$ & 0.28 & 0.15 & $0.17 \dagger$ & 0.28 & 0.15 & $0.17 \dagger$ & 0.32 & 0.16 & $0.19 *$ \\
\hline Ed (yrs) by*sex & 1.01 & 0.77 & 0.11 & 1.07 & 0.77 & 0.11 & 1.08 & 0.78 & 0.12 & 0.85 & 0.82 & 0.09 \\
\hline \multicolumn{13}{|l|}{ Life Events } \\
\hline Relationships & & & & -1.99 & 4.72 & -0.03 & -2.52 & 4.73 & -0.04 & -4.88 & 4.90 & -0.08 \\
\hline Financial & & & & 2.14 & 7.05 & 0.02 & 3.78 & 7.08 & 0.04 & 6.13 & 7.21 & 0.07 \\
\hline Illness & & & & 2.22 & 2.11 & 0.07 & 1.87 & 2.11 & 0.06 & 1.60 & 2.18 & 0.05 \\
\hline Bereavement & & & & 0.87 & 2.24 & 0.02 & 0.69 & 2.25 & 0.02 & 0.94 & 2.34 & 0.03 \\
\hline Employment & & & & -2.82 & 3.85 & -0.04 & -3.31 & 3.84 & -0.05 & -3.26 & 3.91 & -0.05 \\
\hline \multicolumn{13}{|l|}{ Lifestyle } \\
\hline SED activity $1^{a}$ & & & & & & & 0.82 & 0.53 & 0.10 & 0.63 & 0.54 & 0.08 \\
\hline PA activity $2^{\mathrm{b}}$ & & & & & & & -1.70 & 0.86 & $-0.12^{*}$ & -1.62 & 0.90 & $-0.12 \dagger$ \\
\hline FFQ (alcohol) & & & & & & & 0.83 & 0.99 & 0.06 & 0.69 & 1.04 & 0.05 \\
\hline FFQ (unhealthy) & & & & & & & -0.51 & 0.93 & -0.04 & -0.82 & 0.96 & -0.06 \\
\hline FFQ (healthy) & & & & & & & 0.52 & 0.88 & 0.04 & 0.26 & 0.92 & 0.02 \\
\hline \multicolumn{13}{|l|}{ Wellbeing } \\
\hline General Mood & & & & & & & & & & -0.78 & 0.84 & -0.09 \\
\hline Intense Mood & & & & & & & & & & -0.09 & 0.69 & -0.01 \\
\hline Variable Mood & & & & & & & & & & 1.03 & 0.61 & $0.15+$ \\
\hline Hopelessness & & & & & & & & & & -1.44 & 1.14 & -0.11 \\
\hline Resilience & & & & & & & & & & -0.02 & 0.13 & -0.02 \\
\hline Emotional Stress & & & & & & & & & & 0.60 & 0.86 & 0.08 \\
\hline Stress control & & & & & & & & & & 0.82 & 0.82 & 0.11 \\
\hline General mood $^{\mathbf{1}}$ & & & & & & & & & & 1.03 & 1.28 & 0.43 \\
\hline Variable mood $^{\mathbf{1}}$ & & & & & & & & & & -0.40 & 0.88 & -0.04 \\
\hline Intense $\operatorname{mood}^{\mathbf{1}}$ & & & & & & & & & & -0.45 & 1.01 & -0.04 \\
\hline Hopelessness ${ }^{1}$ & & & & & & & & & & 0.33 & 1.69 & 0.18 \\
\hline Resilience ${ }^{\mathbf{1}}$ & & & & & & & & & & 0.08 & 0.18 & 0.05 \\
\hline Emotional stress ${ }^{1}$ & & & & & & & & & & -0.15 & 1.20 & -0.01 \\
\hline Stress control ${ }^{\mathbf{1}}$ & & & & & & & & & & -0.08 & 1.21 & -0.01 \\
\hline Adjusted $\mathrm{R}^{2}$ & & 0.07 & & & 0.06 & & & 0.07 & & & 0.06 & \\
\hline
\end{tabular}

${ }^{*} \mathrm{P}<0.05,{ }^{* *} \mathrm{P}<0.01,+10 \%$ significant.

Abbreviations: SED Sedentary, PA Physical activity; FFQ Food Frequency Questionnaire.

$1=$ controlled for sex.

${ }^{\text {a }}$ Sedentary behaviour at weekdays \& weekends; ${ }^{\text {b }}$ Physical activity in the previous week.

previous studies and ours, together, highlight the importance of sex in explaining relationships between midsection obesity and other interacting factors. The finding that having spent fewer years in education predicted a larger WC in both countries agrees with recent research $[3,6-8]$ and implies a need to target the disadvantaged to prevent and treat mid-section obesity. Although education level can be considered a putative marker of deprivation, lack of data on social class that was comparable across the two countries may limit the scope of our models. As expected, given established scientific opinion $[1,2]$, among those in GB WC was associated with 
sedentary behaviour. Those who reported illness related life events tended to have a larger WC, adding weight to previous observations $[38,39]$ that care providers are more likely to be obese. Consistent with the notion that negative experiences serve to drain resilience [29], illness-related life events and resilience both contributed substantially to WC in the GB sample. It has been argued that awareness of individual vulnerability that may lead to weight gain should be taken into account in health promotion strategies to combat obesity [40]. Assuming that resilience determines how we respond to negative life experiences, the promotion of resilience could reduce such vulnerability. As with BMI, the explanatory power of the GB model (20\%) of WC was greater than that of Portugal (6\%). The relatively poor explanatory power of the Portuguese model of WC could be a function of the relatively smaller sample size.

Previous research has suggested that certain psychological states can trigger or inhibit eating [41] for example, results from the EPIC study have suggested that depression can be associated with dietary fat consumption [12]. Dietary factors, although associated with obesity, however, did not appear to add to the strength of either the GB or the Portuguese models of BMI or WC. It is difficult to interpret this finding with reference to previous studies of stress [19, 20, 23, 24] or depression $[16-19,21,22]$ and obesity since none appear to have considered dietary intake. It is possible that the finding that dietary habits did not predict obesity in either country could reflect limitations inherent in the self-reported food frequency questionnaire (FFQ). That dietary habits in the current study have been found with the anthropometric measures [42], however, implies that the measure was sensitive enough for the purpose of the study.

Previous studies of obesity and well-being have been biased toward the study of negative psychological states (depression and stress) to the neglect of positive traits and states that may be protective against obesity and which could afford opportunities for intervention. Negative psychological traits did not contribute to either model, bringing into question the large body of research which has indicated a link between $\operatorname{WC}[17,18,25,26]$ or BMI $[16-18,21]$ and depression. Existing evidence for a link between depression and obesity is contradictory and our null finding in keeping with several other studies that have found no association between depression and obesity measures [19, 22]. Although validated as part of Beck Depression Inventory, that our research considered hopelessness and not depression per se makes it difficult to make direct comparison with previous studies. The current study, in contrast, has explored not only depression and stress, but also the positive traits, mood and resilience. Although a trait inherent in an individual's personality, resilience can also be construed as a process [32] and as such, has potential to be taught and/or encouraged at the individual level or promoted at group level through the creation of resilience promoting environments. The novel finding that lower resilience predicted higher BMI in Portugal and higher WC in GB suggests that taking measures to promote resilience at both the individual and public health level may reduce obesity in both countries. Resilience could be either or both a driver and a consequence of health behaviour and obesity. That our study has been of crosssectional design, unfortunately, does not enable us to ascertain the causative nature of co-relationships between variables. Further research is required to better understand the interaction between resilience and other psycho-social and lifestyle factors that may contribute to obesity and impact upon the success of potential intervention.

\section{Conclusions}

Our study is unusual in that it has considered in two culturally diverse representative samples of the middle aged and older normal population, both positive and negative psychological constructs and a range of demographic, social and lifestyle factors that may mediate the relationship between psychological well-being and obesity. That the GB models provided a stronger explanation for WC and BMI compared to Portugal could imply the importance of culture in understanding the interplay between psychosocial, lifestyle and psychological factors in the aetiology of obesity which may go some way toward explaining the mixed findings of previous studies. Both the GB and Portuguese models indicate the importance of targeting males and the less educated and of promoting resilience. Our data suggest that obesity prevention efforts in GB should also target care providers and the unemployed and seek to reduce alcohol consumption and increase physical activity. Meanwhile, our results add weight to the theory that research into positive psychological factors has potential to enhance understanding of obesity.

\section{Competing interests}

The authors declare that they have no competing interests.

\section{Acknowledgements}

This research was completed on behalf of the LIPGENE project and funded under the EU $6^{\text {th }}$ Framework Food Quality and Safety Programme, Code FOOD-CT-2003- 505944. Additional funding was provided by the Health Research Board (HRB) Ireland. Ipsos Mori-co-ordinated and conducted the field work.

\section{Author details}

${ }^{1}$ Northern Ireland Centre for Food \& Health (NICHE) School of Biomedical Sciences, University of Ulster, Coleraine, Northern Ireland. ${ }^{2}$ Psychology Research Institute, University of Ulster, Coleraine, Northern Ireland. ${ }^{3}$ University of Porto, Porto, Portugal. ${ }^{4}$ University College Dublin, Dublin, Ireland. 


\section{Authors' contributions}

BSK designed the study and drafted the manuscript, MD conducted statistical analyses and contributed to the manuscript, BB directed the statistical analyses, HP conducted preliminary statistical analyses; MDVA codesigned the study and MG led the research project. All authors have read and approved the final manuscript.

Received: 22 September 2011 Accepted: 11 June 2012

Published: 11 June 2012

\section{References}

1. Finucane MM, Stevens GA, Cowan MJ, Danaei G, Lin JK, Paciorek CJ, Singh GM, Gutierrez HR, Lu YA, Bahalim AN, Farzadfar F, Riley L, Ezzati M: National, regional and global trends in body mass index since 1980: systematic analysis of health examination surveys and epidemiological studies with 960 country years and 9.1 million participants. Lancet 2011, 377:557-567.

2. Bulló M, Garcia-Aloy M, Martínez-González MA, Corella D, Fernández-Ballart JD, Fiol M, Gómez-Gracia E, Estruch R, Ortega-Calvo M, Francisco S, FloresMateo G, Serra-Majem L, Pintó X, Covas M, Ros E, Lamuela-Raventós R, Salas-Salvadó J: Association between a healthy lifestyle and general obesity and abdominal obesity in an elderly population at high cardiovascular risk. Prev Med 2011, 53:155-161.

3. Marcellini F, Giuli C, Papa R, Tirabassi G, Faloia E, Boscaro M, Polito A, Ciarapica D, Zaccaria M, Mocchegiani E: Obesity and body mass index (BMI) in relation to lifestyle and psycho-social aspects. Arch Gerontol Geriatr 2009, 49(Suppl 1):195-206.

4. Lazarou C, Panagiotakos G, Panayiotou G, Matalas A: Overweight and obesity in preadolescent children and their parents in Cyprus: prevalence and associated socio-demographic factors - the CYKIDS study. Obesity Rev 2007, 9:185-193.

5. Ball K, Crawford D: An investigation of psychological, social and environmental correlates of obesity and weight gain in young women. Int J Obesity 2006, 30:1240-1249.

6. Barrington DS, Baquero MC, Borrel LN, Crawford ND: Racial/ethnic disparities in obesity among US-born and foreign-born adults by sex and education. Obesity 2010, 18:422-424.

7. Lawder R, Harding O, Stockton D, Fischbacher C, Brewster D, Chalmers J, Finlayson A, Conway D: Is the Scottish population living dangerously? Prevalence of multiple risk factors: the Scottish Health Survey 2003. BMC Pub Health 2010, 10:art330.

8. Worthy SL, Lokken K, Pilcher K, Boeka A: Demographic and lifestyle variables associated with obesity. Health Ed J 2010, 69:372-380.

9. Kaplan MS, Huguet N, Newsom JT, McFarland BH, Lindsay J: Prevalence and correlates of overweight and obesity among older adults. J Gerontology Series A - Biol Sci \& Med Sci 2003, 58:1018-1030.

10. Ryff CD, Singer BH, Love GD: Positive health: connecting well-being with biology. Phil Trans R Soc 2004, 359:1383-1394.

11. Urry HL, Nitschke JB, Dolski I, Jackson DC, Dalton KM, Mueller CJ, Rosenkranz MA, Ryff CD, Singer BH, Davidson RJ: Making a life worth living. Neural correlates of well-being. Psych Sci 2004, 15:367-372.

12. Kyrozis A, Psaltopoulou T, Stathopoulos P, Trichopoulos D, Vassilopoulos D, Trichopoulou A: Dietary lipids and geriatric depression scale score among elders: the EPIC-Greece cohort. J Psychiatric R 2009, 43:763-769.

13. Stewart-Knox BJ: Psychological underpinnings of metabolic syndrome. Proc Nutr Soc 2005, 64:363-369.

14. McElroy SL, Kotwal R, Malhotra S, Nelson EB, Keck PE, Nemeroff CB: Are mood disorders and obesity related? A review for the mental health professional. J Clin Psychiatry 2004, 65:634-651.

15. Weber-Hamann B, Hentschel F, Kniest A, Deuschle M, Colla M, Lederbogen $F$, Heuser I: Hypercholesteremic depression is associated with increased intra-abdominal fat. Psychosomatic Med 2002, 54:274-277.

16. Kim E, Song JH, Hwang JY, Ahn K, Kim J, Koh YH, Park MH, Jo SA: Obesity and depressive symptoms in elderly Koreans: Evidence for the "Jolly Fat" hypothesis from the Ansan Geriatric (AGE) Study. Arch Gerontology \& Geriatrics 2010, 51:231-234

17. Rice MC, Katzel LI, Waldstein SR: Sex-specific associations of depressive symptoms and cardiovascular risk factors in older adults. Aging Ment Health 2010, 14:405-410.
18. Zaninotto P, Pierce $M$, Breeze $E$, de Oliveira C, Kumari M: BMI and waist circumference as predictors of well-being in older adults: findings from the English Longitudinal Study of Ageing. Obesity 2010, 18:1981-1987.

19. Ucok K, Genc A, Akkaya M, Gonul Y, Uygur R, Mollaoglu H, Songur A: Association Analyses among Anthropometric Measurements, Exercise Capacities, Pulmonary Functions, Lateralization and Psychological Status in Young Adults. Neurology Psychiatry \& Brain Research 2009, 16:35-40.

20. Lahiri K, Rettig-Ewen V, Bohm M, Laufs U: Perceived psychosocial stress and cardiovascular risk factors in obese and non-obese patients. Clin Res Cardiology 2007, 96:365-374.

21. Ho RCM, Niti M, Kua EH, Ng TP: Body mass index, waist circumference, waist-hip ratio and depressive symptoms in Chinese elderly: a population-based study. Int J Geriatric Psychiatry 2008, 23:401-408.

22. Hach I, Ruhl UE, Klotsche J, Klose M, Jacobi F: Associations between waist circumference and depressive disorders. J Affective Disorders 2006, 92:305-308.

23. Bove M, Carnevali L, Cicero AFG, Grandi E, Gaddoni M, Noera G, Gaddi AV: Psychosocial factors and metabolic parameters: Is there any association in elderly people? The Massa Lombarda Project. Aging Ment Health 2010 14:801-806.

24. Farag NH, Moore WE, Lovallo WR, Mills PJ, Khandrika S, Eichner JE: Hypothalamic-Pituitary-Adrenal Axis Function: Relative Contributions of Perceived Stress and Obesity in Women. J Women's Health 2008, 17:1647-1655

25. Beydoun MA, Kuczmarski MTF, Mason MA, Ling SM, Evans MK Zonderman $\mathrm{AB}$ : Role of depressive symptoms in explaining socioeconomic status disparities in dietary quality and central adiposity among US adults: a structural equation modeling approach. Am J Clin Nutr 2009, 90:1084-1095.

26. Toker S, Shirom A, Melamed S: Depression and the metabolic syndrome: gender-dependent associations. Depress Anxiety 2008, 5:661-669.

27. Luthar SS, Cicchetti D: The construct of resilience: implications for intervention and social policy. Dev Psychopathol 2000, 12:857-885

28. Underwood B, Froming WJ: The mood survey - A personality measure of happy and sad moods. J Personality \& Assessment 1980 44:404-414.

29. Simeon D, Yahuda R, Cunhill R, Knutelska M, Putnam FW, Smith LM: Factors associated with resilience in healthy adults. Psychoneuroendocrinology 2007, 32:1149-1152

30. Simpson EEA, O'Connor JM, Livingstone MBE, Rae G, Stewart-Knox BJ, Andriollo-Sanchez M, Toti E, Meunier N, Ferry M, Polito A, Kelly M, Wallace JMW, Coudray C: Health and lifestyle characteristics of older European adults: the Zenith study. Eur J Clin Nutr 2005, 59:S13-S21.

31. Wagnild GM, Young HM: Development and psychometric evaluation of the resilience scale. J Nursing Measurement 1993, 1:165-178.

32. Schumacher J, Leppert K, Gunzelmann T, Strauss B, Brahler E: The resilience scale - a questionnaire to assess resilience as a personality characteristic. Z Klin Psychol Psychiatr Psychother 2005, 53:16-39.

33. Beck AT, Weissman A, Lester D, Trexler L: The measurement of pessimism: The Hopelessness Scale. J Consulting \& Clin Psychology 1974, 42:861-865.

34. Cohen S, Williamson GM: Perceived stress in a probability sample of the United States. In The Social Psychology of Health. Edited by Spacapan S, Oskamp S. Newbury Park, CA: Sage; 1998:31-67.

35. Cohen S, Kamarck T, Mermelstein R: A global measure of perceived stress. $J$ Health \& Soc Behaviour 1983, 24:385-396.

36. Mooy JM, Bouter LM, de Vries H, Heine RJ, Grootenhuis PA: Major stressful life events in relation to prevalence of undetected Type 2 Diabetes. Diabetes Care 2000, 23:2,197-201.

37. Tabachnick BG, Fidell LS: Using Multivariate Statistics (3rd ed). New York: Harper Collins; 1996.

38. Barrow S, Harrison RA: Unsung heroes who put their lives at risk? Informal caring, health and neighbourhood attachment. J Pub Health 2005, 27:292-297.

39. Barry D, Petry N: Gender differences in associations between stressful life events and body mass index. Prev Med 2008, 47:498-503. 
40. Malterud $\mathrm{K}$, Tonstad S: Preventing obesity: challenges and pitfalls for health promotion. Patient Edu Couns 2009, 76:254-259.

41. Jasen A, Havermans R, Nederkoorn C, Roefs A: Jolly fat or sad fat? Subtyping non-eating disordered overweight and obesity along an affect dimension. Appetite 2008, 51:635-640.

42. Duffy M, Stewart-Knox B, Parr H, Bunting B, de Almeida M, Gibney M: Associations between resilience, frequency of food group consumption and anthropometric measures. Proc Nutr Soc 2009, 68:150.

doi:10.1186/1471-2458-12-424

Cite this article as: Stewart-Knox et al:: Associations between obesity

(BMI and waist circumference) and socio-demographic factors, physical activity, dietary habits, life events, resilience, mood, perceived stress and hopelessness in healthy older Europeans. BMC Public Health 2012 12:424.

\section{Submit your next manuscript to BioMed Central and take full advantage of:}

- Convenient online submission

- Thorough peer review

- No space constraints or color figure charges

- Immediate publication on acceptance

- Inclusion in PubMed, CAS, Scopus and Google Scholar

- Research which is freely available for redistribution 